\title{
Detailed analysis of the clinical effects of cell therapy for thoracolumbar spinal cord injury: an original study
}

\author{
Alok Sharma' \\ Nandini Gokulchandran' \\ Hemangi Sane ${ }^{2}$ \\ Prerna Badhe' \\ Pooja Kulkarni² \\ Mamta Lohia ${ }^{3}$ \\ Anjana Nagrajan ${ }^{3}$ \\ Nancy Thomas ${ }^{3}$
}

'Department of Medical Services and Clinical Research, ${ }^{2}$ Department of Research and Development,

${ }^{3}$ Department of Neurorehabilitation, NeuroGen Brain and Spine Institute, Surana Sethia Hospital and Research Centre, Chembur, Mumbai, India

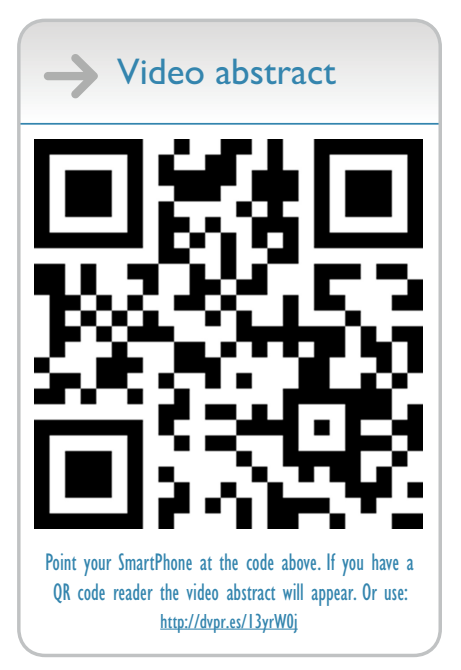

Correspondence: Alok Sharma NeuroGen Brain and Spine Institute, Surana Sethia Hospital and Research Centre, Suman Nagar, Sion-Trombay Road, Chembur, Mumbai 40007I, India Tel +9l 02225283706

Fax+91 02225292250

Email alok276@gmail.com
This article was published in the following Dove Press journal:

Journal of Neurorestoratology

25 July 2013

Number of times this article has been viewed

Background: Cell therapy is amongst the most promising treatment strategies in spinal cord injury (SCI) because it focuses on repair. There are many published animal studies and a few human trials showing remarkable results with various cell types. The level of SCI determines whether paraplegia or quadriplegia is present, and greatly influences recovery. The purpose of this study was to determine the significance of the clinical effects and long-term safety of intrathecal administration of autologous bone marrow-derived mononuclear cells, along with changes in functional independence and quality of life in patients with thoracolumbar SCI.

Methods: We undertook a retrospective analysis of a clinical study in which a nonrandomized sample of 110 patients with thoracolumbar SCI underwent autologous bone marrow-derived mononuclear cell transplantation intrathecally and subsequent neurorehabilitation, with a mean follow-up of 2 years \pm 1 month. Changes on any parameters were recorded at follow-up. The data were analyzed using the Wilcoxon's signed-rank test and McNemar's test. Functional Independence Measure and American Spinal Injury Association (ASIA) scores were recorded, and a detailed neurological assessment was performed.

Results: Overall improvement was seen in $91 \%$ of patients, including reduction in spasticity, partial sensory recovery, and improvement in trunk control, postural hypotension, bladder management, mobility, activities of daily living, and functional independence. A significant association of these symptomatic improvements with the cell therapy intervention was established by the statistical analysis. Some patients showed a shift on the ASIA scale and changes in electrophysiological studies or functional magnetic resonance imaging. No major side effects were noted.

Conclusion: In patients with thoracolumbar SCI, there were statistically significant beneficial effects, both symptomatic and functional, from intrathecal autologous bone marrow-derived mononuclear cell therapy and rehabilitation. This was a safe and viable therapeutic option with no long-term side effects at 2 years. This analytical study is an early documentation of cell therapy, and can be used as a guide to devise larger more refined clinical trials.

Keywords: cell therapy, spinal cord injury, autologous, bone marrow-derived mononuclear cells, intrathecal administration

\section{Introduction}

Spinal cord injury (SCI) results in severe neurological damage, and is often caused by road traffic accidents (RTAs) or falls from height. Specifically, SCI results in paralysis, which severely affects quality of life. Recovery from SCI is difficult because the injured spinal cord loses its ability to regenerate lost or damaged cells and re-establish functional neural connections. Because there is no effective medical therapy available, several studies have been carried out in animal models, which have included rehabilitation, pharmacological treatment, and cell therapy. ${ }^{1}$ Cell therapy is amongst the most 
promising treatment strategies because it focuses on replacing the lost or damaged cells with progenitor or stem cells, leading to further axonal growth, remyelination of axons, and reduction of neuronal degeneration. ${ }^{2,3}$ In this study, we performed autologous bone marrow-derived mononuclear cell (BMMNC) transplantation in 110 patients with SCI to study the therapeutic effects of cell therapy. BMMNCs were used because they are readily available in abundance, and unlike embryonic cells, do not involve any ethical issues.

\section{Materials and methods}

The study was designed as a retrospective analysis of a clinical trial conducted in a nonrandomized sample of SCI patients who underwent autologous BMMNC transplantation. The patients were selected based on the inclusion criterion in paragraph 35 of the Declaration of Helsinki regarding ethical principles for medical research involving human subjects. ${ }^{4}$ Patients with documented SCI on magnetic resonance imaging (MRI) or computed tomography scan were selected, and were included irrespective of the cause, extent, or completeness of their injury. Exclusion criteria were the presence of respiratory distress, acute infections such as human immunodeficiency virus, hepatitis B virus, or hepatitis $\mathrm{C}$ virus, malignancy, and other acute medical conditions, including respiratory tract infection or fever, and pregnancy or breastfeeding.

\section{Sample population}

The characteristics of the 110 SCI patients included in the study are shown in Table 1 . The mean age of the study group was 35 years. The patients had typical sequelae of SCI, including motor weakness, sensory loss, loss of bladder and bowel control and sensation, and spasticity (Figure 1). Ninety-nine $(90 \%)$ of the patients were American Spinal Injury Association (ASIA) grade A, ten (9\%) were grade B, and one $(0.9 \%)$ was grade $C$. In total, $101(92 \%)$ cases had undergone surgery, while $62(56 \%)$ had undergone rehabilitation before treatment with BMMNCs. The majority of the patients were in the plateau phase of recovery.

\section{Procedure}

The protocol was reviewed and approved by the Institutional Committee for Stem Cell Research and Therapy in accordance with the Indian Council of Medical Research guidelines. An informed consent was obtained from all patients and their families. Before therapy, all patients underwent extensive evaluation by medical and rehabilitation experts. Pre-evaluation included a complete neurological examination,
Table I Patient demographic and clinical data

\begin{tabular}{ll}
\hline Patients $(\mathbf{n}=\mathbf{I} \mathbf{~} \mathbf{0})$ & \\
Gender & 92 \\
Male & 18 \\
Female & \\
Age & 61 \\
$\quad<35$ years & 49 \\
$>35$ years & \\
Level of SCI & 98 \\
Dorsal & 12 \\
Lumbar & \\
Type of injury & 101 \\
Traumatic & 9 \\
Nontraumatic & \\
Cause of trauma & 69 \\
RTA & 32 \\
Others & \\
Duration since SCl, years & 7 \\
$<$ I & \\
I-3 & 35 \\
$3-5$ & 28 \\
$>5$ & 40 \\
\hline Abbreviations SCl, spina
\end{tabular}

Abbreviations: SCl, spinal cord injury; RTA, road traffic accident.

psychological examination, manual muscle testing, and evaluation on scales such as the Functional Independence Measure (FIM) and ASIA. The patients were assessed for fitness pretherapy using routine blood tests and X-rays. Specific tests, such as MRI spine, functional MRI, electromyography, somatosensory evoked potentials, and nerve conduction velocity, were also performed. The mean followup period was 2 years \pm 1 month.

\section{Isolation and administration of autologous bone marrow cells}

Granulocyte-colony stimulating factor injections were administered 48 hours and 24 hours prior to treatment to stimulate CD34+ cells and promote their survival and replication. ${ }^{5,6}$ Bone marrow aspiration was carried out under local or general anesthesia depending on the individual case. Approximately $100 \mathrm{~mL}$ (80-120 mL, based on age and body weight) of bone marrow was aspirated from the anterior superior iliac crest bone using a standard procedure. Mononucleocytes were obtained after density gradient separation. A viability count of the isolated mononucleocytes was done, and average viability was found to be $96.18 \%$. The mononucleocytes were checked for CD34+ by fluorescence activated cell sorting. Body weight $\times 10^{6}$ mononucleocytes were injected intrathecally into L4-L5 immediately post separation using an $18 \mathrm{G}$ Tuohy needle and catheter. Intravenous methylprednisolone $(30 \mathrm{mg} / \mathrm{kg}$ 


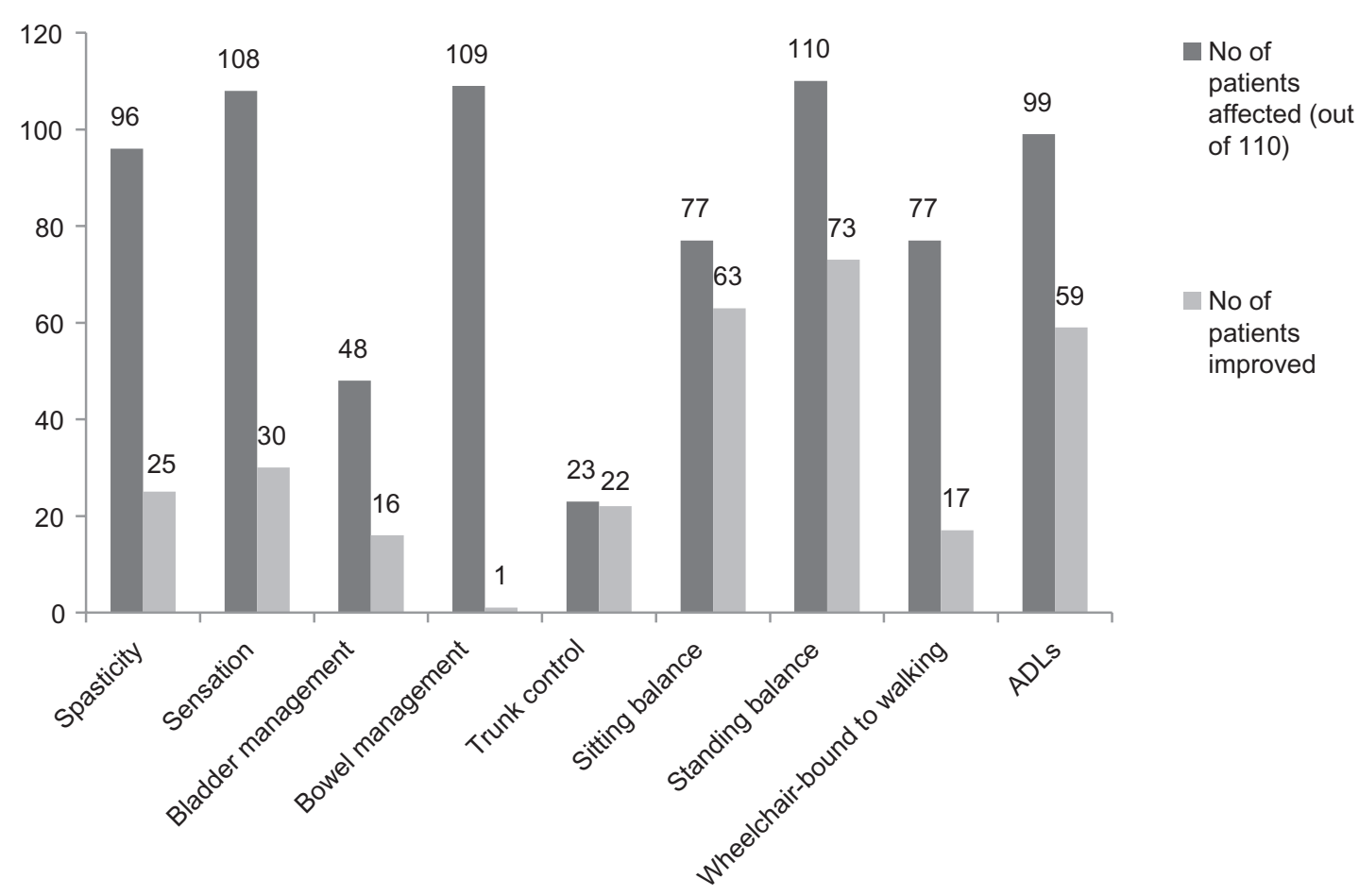

Figure I Symptomatic improvements in patients with spinal cord injury after stem cell therapy. The $\mathrm{x}$ axis denotes symptoms presented in the patient population and the $y$ axis denotes the number of patients.

Abbreviation: ADLs, activities of daily living.

over one hour) was administered simultaneously with the cells.

\section{Neurorehabilitation}

All the patients underwent neurorehabilitation, including physiotherapy, occupational therapy, and psychological therapy, for a period of 6 months to 1 year. The exercise protocol was planned specifically for individual patients, as per the detailed assessment done before therapy.

\section{Outcome measures}

All patients included in this study have been followed up for at least 4 years thus far. Patients were followed up at 3 months and 6 months following stem cell transplantation and once yearly thereafter. A detailed neurological evaluation was performed by physicians and therapists to note symptomatic changes. FIM scores were used to assess changes in functional independence, reflecting improvement in quality of life. This scoring system was developed to evaluate the progress of rehabilitation in patients with multiple disabilities, ${ }^{7}$ and its reliability and validity is high across many disability groups, including SCI. ${ }^{8}$ The ASIA scale was used to monitor motor and sensory recovery. This is the most commonly used outcome measurement tool in use for SCI today. This scale was originally developed as a classification system, but has evolved in such a way that elements of the examination on which the classification is based are used as outcome measures. ${ }^{9}$ Functional MRI and electromyography/nerve conduction velocity studies were repeated to demonstrate objective evidence of the effects of cell therapy.

\section{Statistical analysis}

The data were analyzed using SPSS statistical software version 17.0 (SPSS Inc., Chicago, IL, USA). The Wilcoxon signed-rank test to establish the significance of changes in FIM score. A frequency distribution was computed for the changes observed in symptoms. The proportions of these frequencies were analyzed using the McNemar's test to establish the significance of the association between symptomatic changes and the cell therapy intervention.

\section{Results}

One hundred and ten paraplegic SCI patients underwent autologous BMMNC transplantation. On follow-up at a mean of 2 years \pm 1 month, 100 cases (91\%) showed symptomatic, investigational, and functional improvement. A reduction in spasticity was found in $26 \%$ of cases, partial sensory recovery in $28 \%$, improved trunk control in $96 \%$, and less postural hypotension in $100 \%$. There was also an improvement in bladder management with respect to a shift from indwelling and condom catheters to intermittent self-catheterization 
in $33 \%$ of cases. Further, 22\% of wheelchair-bound cases started walking and $60 \%$ of patients whose activities of daily living were affected showed improvement (Figure 1). A statistically significant association between these symptomatic improvements and the stem cell intervention was established by McNemar's test (Table 2).

Two of the 110 patients shifted from grade $\mathrm{A}$ to $\mathrm{C}$ on the ASIA scale, one shifted from grade B to C, and eight shifted from grade A to B (Figure 2). The median preintervention FIM score was 71 and after intervention was 79.5. Fifty-nine patients showed a significant change in FIM score (Figures 3 and 4). This was further supported by the statistical analysis, which showed a $Z$ value of -6.685 and a two-tailed $P$ value of $\leq 0.0001$ (Wilcoxon's signed-rank test). A significant functional improvement was evident following intervention. On electrophysiological studies, two patients showed improvement, and one showed an improvement on functional MRI.

No major side effects were recorded post transplantation. However, minor procedure-related side effects, including headache, nausea, vomiting, and backache, were noted in a few cases and controlled with medication. Two patients died within 3 months of the intervention due to pulmonary embolism unrelated to the procedure or cell therapy.

\section{Discussion}

Cell transplantation has been studied extensively in the past two decades in the setting of central nervous system injury. A variety of cells have been used, including embryonic cells, neural cells, umbilical cord blood cells, bone marrow-derived stromal cells, Schwann cells, and olfactory ensheathing cells. ${ }^{10-12}$ The findings of several animal and human studies have supported the role of cell transplantation in spinal cord repair. ${ }^{13-15}$ Due to the multifactorial pathophysiology of SCI, cell transplantation holds great potential.
The objective of our study was to evaluate the safety, feasibility, and efficacy of autologous BMMNCs in the treatment of patients with chronic SCI. These mononucleocytes contain hematopoietic stem cells, tissue-specific progenitor cells, stromal cells, and specialized blood cells in different stages of development. They are multipotent, with definitive in vivo and in vitro neuronal differentiation and no associated immunological or ethical issues. It has been reported that use of whole BMMNCs is more successful than methods using subfractionated cell preparations. ${ }^{16}$ The mixture of cells involved is known to encourage distinct angiogenic properties and promote vascular repair. ${ }^{17}$ These cells have the capacity to mobilize and exert their reparative effects at the site of injury. It has been observed in murine models that transplanted bone marrow stromal cells migrate and attach to injured neural tissue. Within 3 weeks, the cells release trophic factors to stop degeneration of neurons and glial cells, and stimulate differentiation of neural stem cells in injured spinal cord tissue. ${ }^{15,18,19}$ They also enhance angiogenesis and contribute to neovascularization by producing signaling molecules, such as vascular endothelial growth factor and fibroblast growth factor $2 .{ }^{20}$ Bone marrow stromal cells and BMMNCs have been found to replace white and gray matter, with neuronal and axonal regeneration, proliferation, myelination, and neovascularization of astrocytes, leading to further functional improvements in animal models. . $^{15,21,22}$

We included 110 chronic SCI cases that were traumatic or nontraumatic in nature and underwent intrathecal administration of BMMNCs. Intrathecal delivery is minimally invasive and has been shown to deliver cells to contused spinal cord tissues and exert a significant beneficial effect by reducing injury size in models of spinal cord contusion. ${ }^{23}$ It has also been shown that intrathecal delivery of mesenchymal stem cells appears to be better than intravenous delivery to the injured spinal cord in terms of cell engraftment, tissue sparing, and a reduced immune response. ${ }^{24}$ Although intraspinal administration of cells has

Table 2 Statistical significance for each symptomatic/functional change using McNemar's test

\begin{tabular}{lllll}
\hline Symptom/function & Affected patients (n of I I 0) & Patients improved (n) & Chi-square value $^{\dagger}$ & $\boldsymbol{P}_{\text {value }}^{\#}$ \\
\hline Spasticity & 96 & 25 & 23.04 & $<0.000 \mathrm{I}$ \\
Sensation & 108 & 30 & 28.033 & $<0.000 \mathrm{I}$ \\
Bladder management & 48 & 16 & 14.06 & 0.0002 \\
Bowel management & 109 & 1 & 0 & $1.000^{*}$ \\
Trunk control & 23 & 22 & 20.045 & $<0.000 \mathrm{I}$ \\
Sitting balance & 77 & 63 & 61.016 & $<0.000 \mathrm{I}$ \\
Standing balance & 110 & 73 & 70.014 & $<0.000 \mathrm{I}$ \\
Wheelchair-bound to walking & 77 & 17 & 15.059 & 0.0001 \\
ADLs & 99 & 59 & 57.017 & $<0.000 \mathrm{I}$ \\
\hline
\end{tabular}

Notes: "Significant at $P \leq 0.05 ;{ }^{\dagger}$ Chi-square value at one degree of freedom; $* P$ value insignificant for improvement in bowel management.

Abbreviation: ADLs, activities of daily living. 


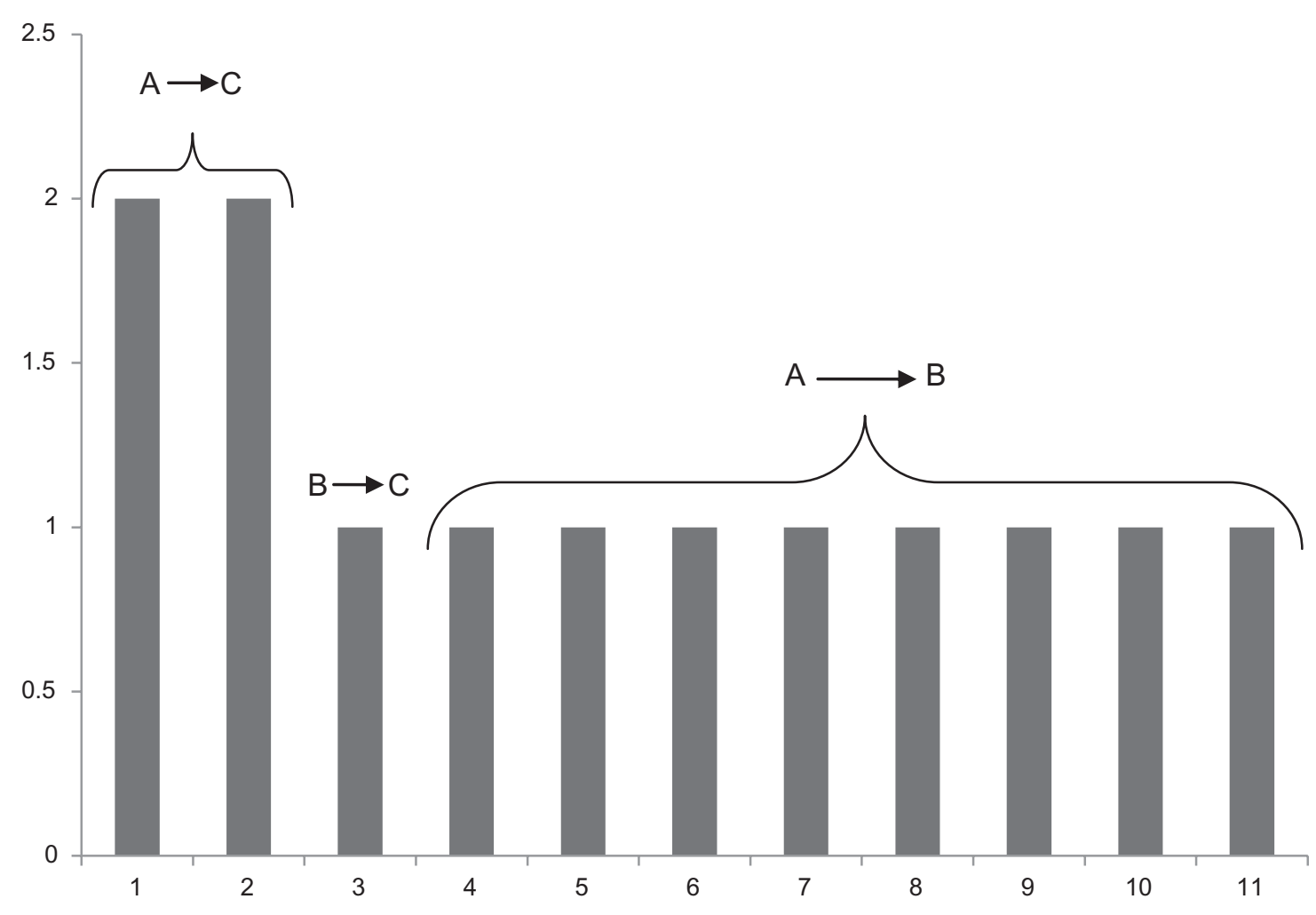

Figure 2 Change in American Spinal Injury Association scores in patients with spinal cord injury after stem cell therapy. Two patients shifted from grade A to $C$, one from grade $B$ to $C$, and eight from grade $A$ to $B$. Individual patients are marked on the $x$-axis, and each level of change is given one point on the $y$-axis. Therefore, the shift from $A$ to $C$ is 2 points and $A$ to $B$ and $B$ to $C$ are one point each.

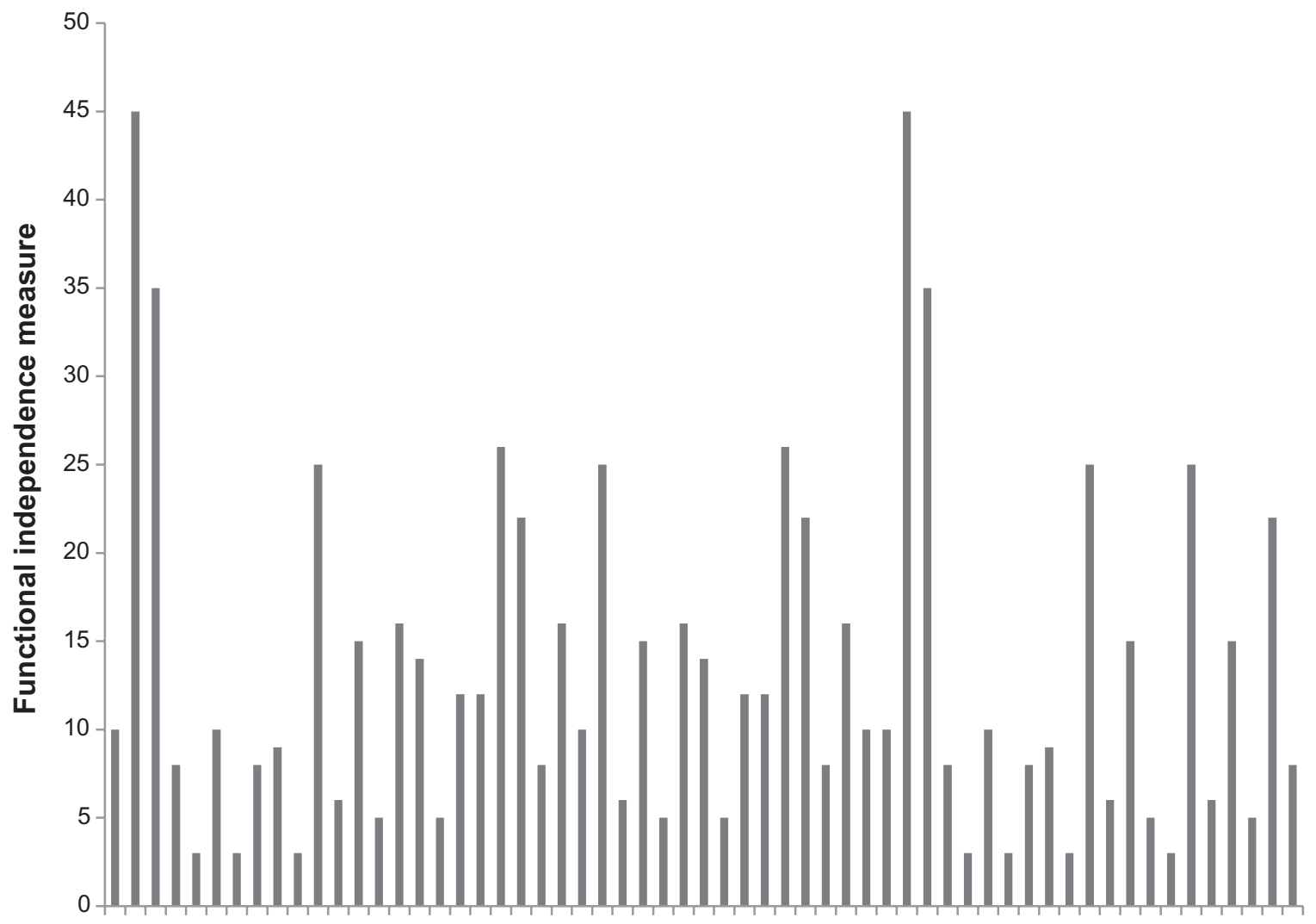

Figure 3 Change in Functional Independence Measure score in 59 patients after stem cell therapy. 


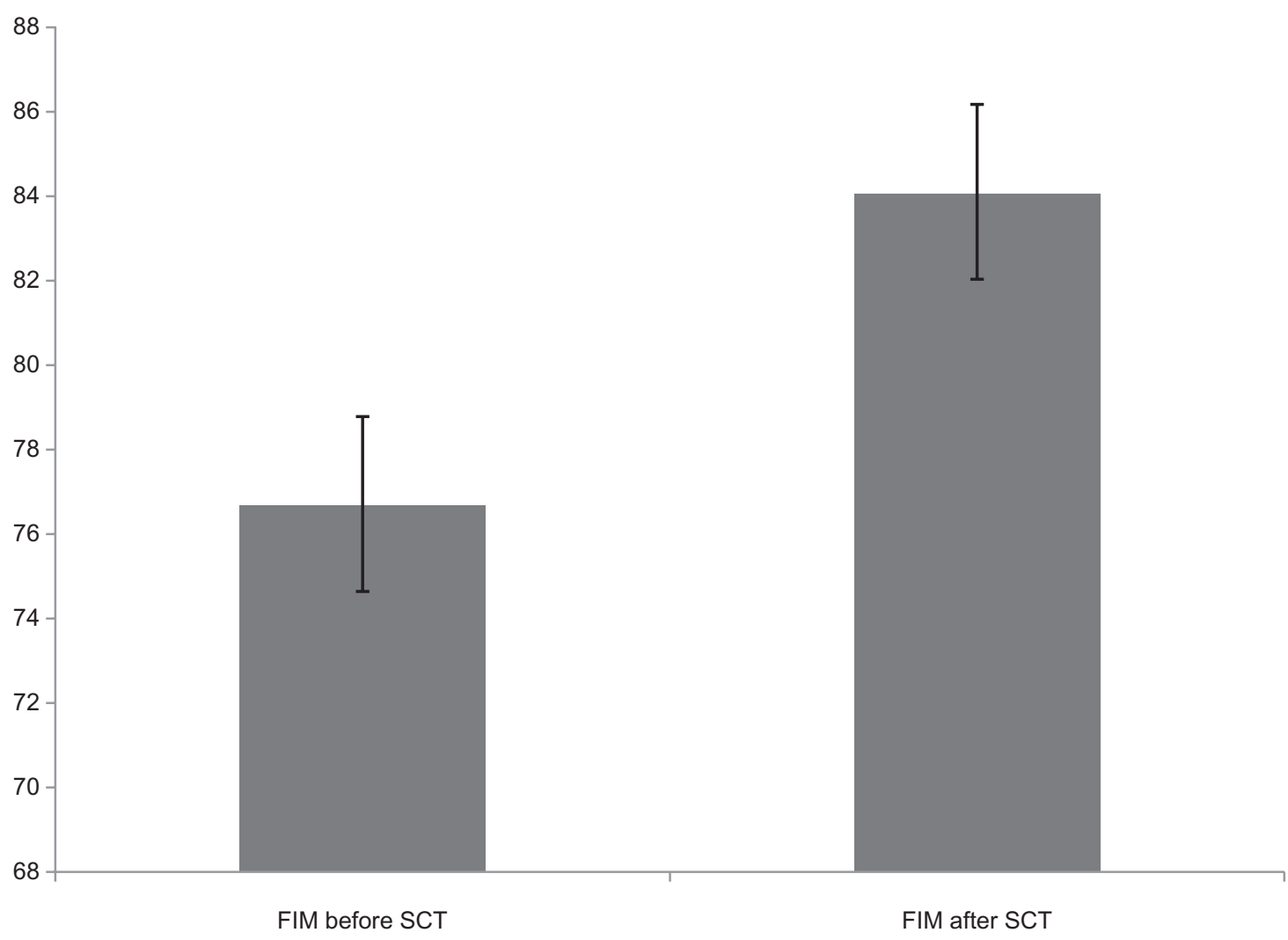

Figure 4 Effect of stem cell therapy on mean FIM scores after stem cell therapy. Abbreviations: FIM, Functional Independence Measure; SCT, stem cell therapy.

been found to be effective in SCI, it is believed that this route of administration leads to additional tissue damage. This procedure is also more invasive, requires general anesthesia, and is associated with a considerable risk of complications. ${ }^{23}$ In combination with cell transplantation, our patients also underwent extensive rehabilitation. In acute SCI, it has been observed that a combination of bone marrow stem cell therapy and exercise training results in significant functional improvement. ${ }^{25}$

In our study, after a mean follow-up of 2 years \pm 1 month, $91 \%$ of patients showed symptomatic and functional improvements. On further detailed analysis, a number of factors were taken into consideration, and are discussed as follows.

\section{Gender}

Forty-eight of 92 (52.17\%) males showed improved FIM scores following cell transplantation versus 11 of 18 females (61.11\%). The higher response rate in women may be attributed to the neuroprotective effects of estrogen. ${ }^{26}$

\section{Age}

The sample population was grouped into those younger and older than 35 years, given that 35 years was the mean age of the sample. Improvement was documented in $61.01 \%$ of those younger than 35 years versus $46.94 \%$ of those older than 35 years, indicating that younger patients respond better to cell transplantation, possibly for multiple reasons, including a greater number of stem cells being available, greater neuroplasticity, and more ability to exercise.

\section{Type of injury}

Of the 110 SCI cases in this study, $91.82 \%$ of injuries were traumatic and the rest were nontraumatic. Although the numbers are not comparable based on percentages, the improvements observed were more pronounced in the traumatic cases, ie, 57 of $98(58.16 \%)$ as compared with two of nine (22.22\%) nontraumatic cases. Nontraumatic injuries are more difficult to repair because the disease process and resulting damage may be ongoing and diffuse, resulting in both anatomical and intrinsic functional loss of neurons.

\section{Cause of trauma}

FIM improved in $50.72 \%$ of RTA cases as compared with $68.75 \%$ in non-RTA cases. Non-RTA cases included bullet injuries, falls from height, and objects falling on the spine. Those with an RTA may have had more severe and extensive injury and multiple injuries at other anatomical sites. 


\section{Chronicity of injury}

Improvement in FIM score was seen in 57\% of those who sustained their injury within the previous year, $60 \%$ of those in the $1-3$-year group, $71 \%$ in the 3-5-year group, and 35\% in the more than 5 years group (Figure 5). The least improvement was seen in patients who were more than 5 years out from their SCI. This is probably because increasing chronicity makes injury repair more difficult; these patients may have already learned fixed patterns of functioning, and worsening of complications like contractures and longer duration of dependency hamper recovery.

\section{Level of injury}

The proportions of patients showing improvement were $48 \%$ in those with SCI at T1-T4, 48\% at T5-T8, 64\% at T9-T12, and $41 \%$ at lumbar levels of injury, as shown in Figure 6. Those with a lower level of injury, ie, at the lumbar spine, already had a high FIM score before intervention. Although qualitative changes were noted in their functioning, these high pre-FIM scores may have masked any quantitative changes.

\section{Rehabilitation prior to cell therapy}

Sixty-two patients had undergone extensive neurorehabilitation before intervention with cell therapy, and $50 \%$ of these patients showed further improvement. This observation suggests that the improvement seen may be directly associated with the effect of cell therapy. Twenty-nine of 48 (60.42\%) patients who had not undergone neurorehabilitation before cell therapy showed improved FIM scores after intervention. The similarity of the percentages in both groups indicates that cell therapy independently exerted beneficial effects.

\section{Relationship between symptomatic/ functional changes and cell therapy}

Most patients showed symptomatic improvement in spasticity and balance during the first few weeks after cell therapy, which was followed by improvement in sensation and in trunk muscle strength and control over a period of 6 months. Dramatic improvement in bed mobility (rolling in bed, getting up from supine to sit, bed transfers, shifting sidewards, forward and backwards in bed) was seen in a large number of patients (92.86\%), possibly due to the significant improvements in trunk control (Table 2).

Partial sensory recovery was seen in $27.77 \%$ of patients following intervention, with tingling and burning sensation being the earliest sign of recovery, possibly as a result of the active repair of damaged nerves by BMMNCs,

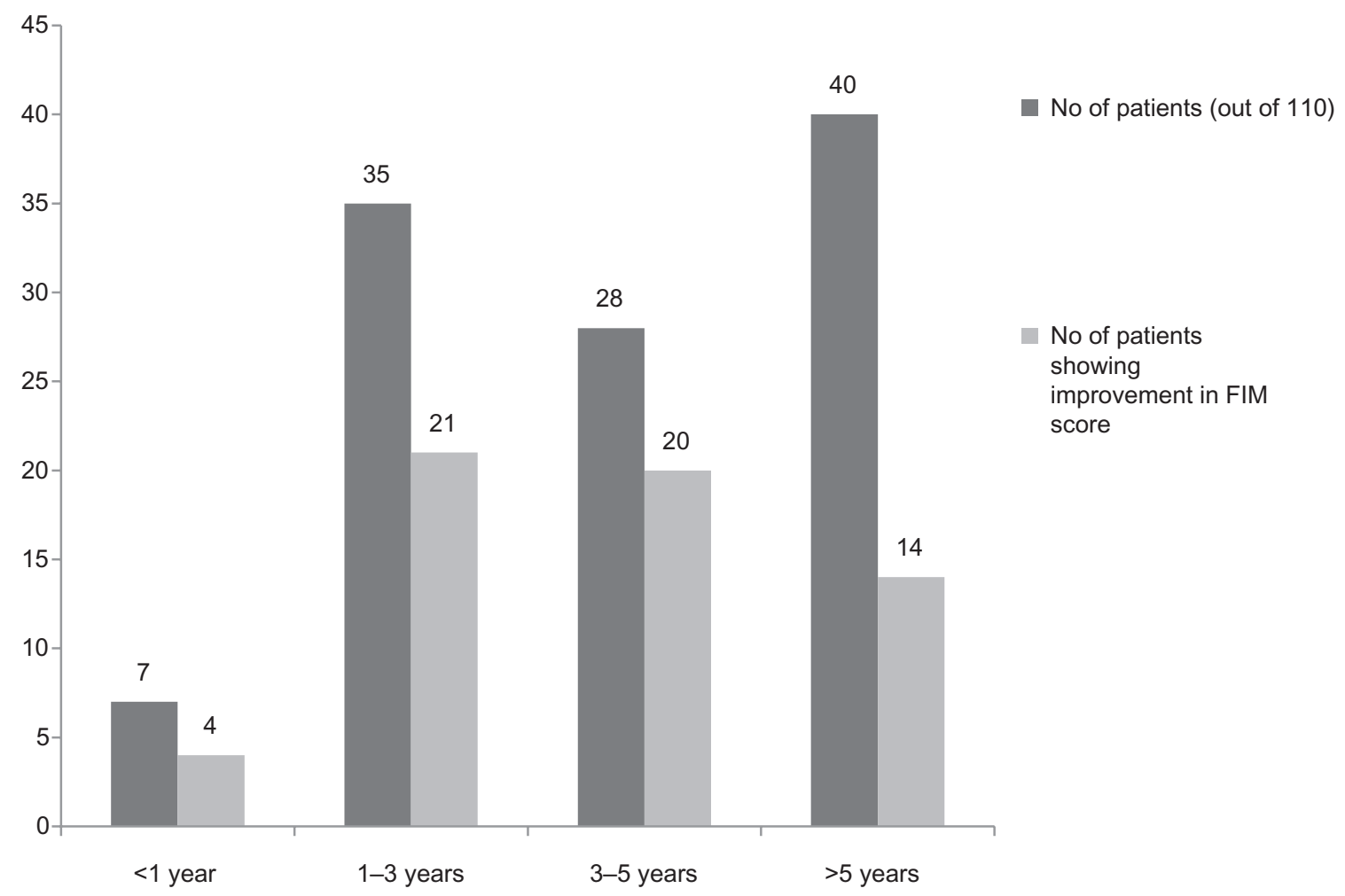

Figure $\mathbf{5}$ Improvement in FIM score after stem cell therapy based on chronicity of spinal cord injury. Abbreviation: FIM, Functional Independence Measure. 


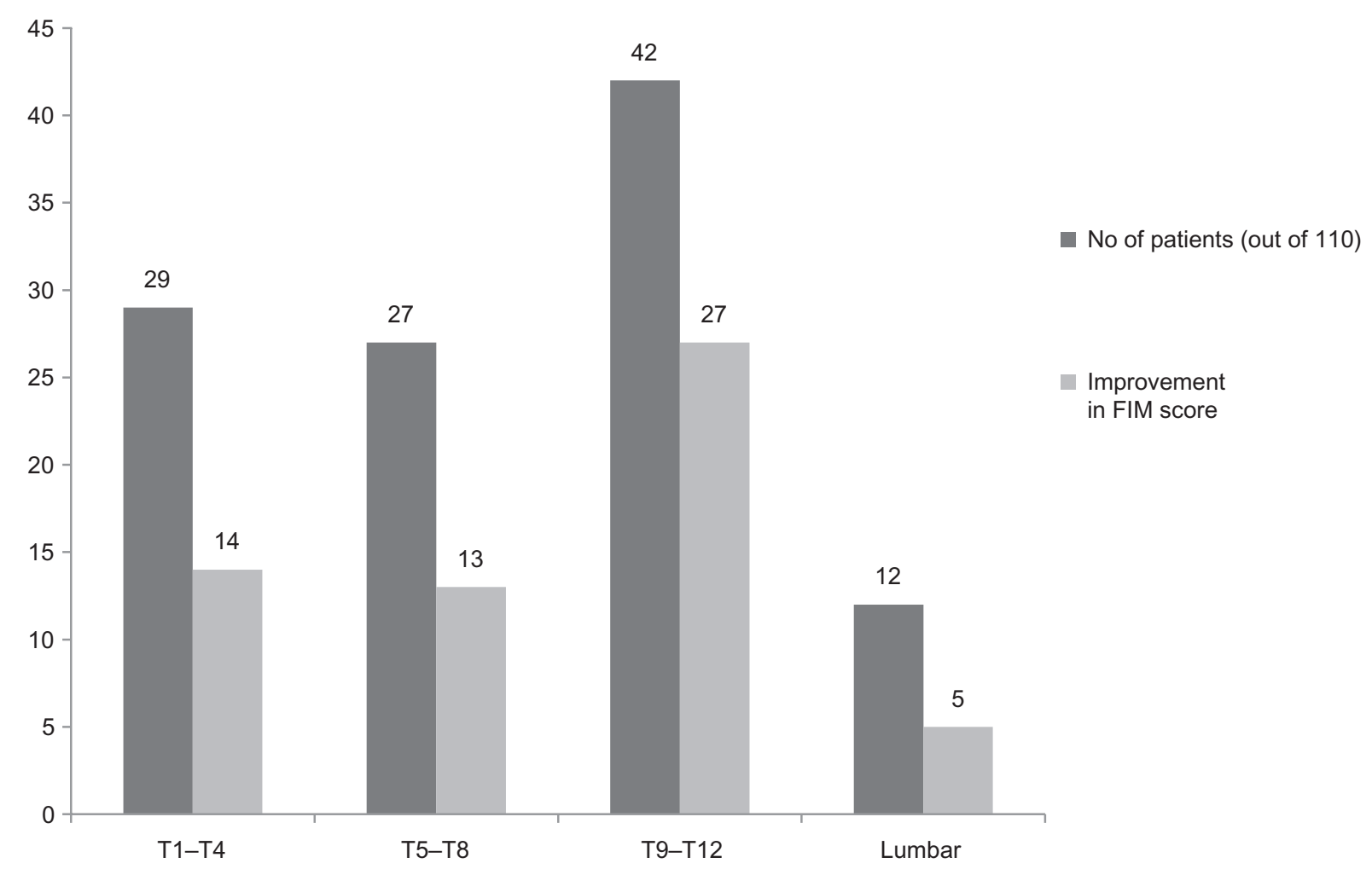

Figure 6 Improvement in FIM score after stem cell therapy based on different cord levels of injury. Abbreviation: FIM, Functional Independence Measure.

which was evident on electromyography/nerve conduction velocity studies and functional MRI in some patients (Table 3). Preintervention symptoms of postural hypotension resolved after cell therapy in five patients.

Bladder management is often a challenging problem in SCI patients, who often have to use an indwelling or condom catheter due to loss of bladder sensation and control. These devices pose a high risk of infection, complications, renal impairment, and social embarrassment. Therefore, addressing this issue is of paramount importance for these patients. In this study, 48 of the 110 patients were using a Foley or condom catheter before cell therapy, and 16 of these patients

Table 3 Objective improvements evident on electromyography $(\mathbf{A})$ and functional magnetic resonance imaging (B) after stem cell therapy in selected patients

\begin{tabular}{|c|c|c|c|}
\hline (A) & Nerve/sites & Amplitude 2-4 mV (before) & Amplitude 2-4 mV (after) \\
\hline \multirow[t]{5}{*}{ Patient I } & $\mathrm{R}$ tibial (knee)-AH ankle & 3.5 & 5.4 \\
\hline & R tibial (knee)-AH knee & 2.7 & 5.1 \\
\hline & L tibial (knee)-AH ankle & 4.1 & 5.7 \\
\hline & R tibial (knee)-gastrocnemius knee & 7.2 & 14.8 \\
\hline & L tibial (knee)-gastrocnemius knee & 10.2 & 11.7 \\
\hline \multirow[t]{7}{*}{ Patient 2} & L common peroneal-EDB ankle & 0.8 & 3.0 \\
\hline & R common peroneal - tibialis anterior, fibular head & 1.6 & 3.4 \\
\hline & L common peroneal - tibialis anterior, fibular head & 1.8 & 4.3 \\
\hline & $\mathrm{R}$ tibial (knee)-AH ankle & 7.0 & 8.0 \\
\hline & L tibial (knee)-AH ankle & 7.9 & 8.3 \\
\hline & R tibial (knee)-gastrocnemius knee & 6.2 & 18.7 \\
\hline & L tibial (knee)-gastrocnemius knee & 2.5 & 17.2 \\
\hline (B) & Functional MRI (before) & Functional MRI (after) & \\
\hline Patient I & No activity in the pre and post central gyri & Activation in the right precentra & \\
\hline
\end{tabular}

Abbreviations: $\mathrm{AH}$, abductor hallucis; $\mathrm{EDB}$, extensor digitorum brevis; MRI, magnetic resonance imaging; $\mathrm{R}$, right; L, left. 
were able to switch to intermittent self-catheterization, which helped to improve bladder management and thereby quality of life. This result was statistically significant (Table 2). In contrast, there was no improvement seen in bowel management in this study.

Fifty patients who were initially unable to stand post SCI could stand with assistance after cell therapy. For the first time since their SCI, 17 patients started assisted walking following cell therapy. These improvements were perceived as of great magnitude by the patients.

Following on from the above symptomatic improvements, mobility (assisted walking, climbing stairs) improved, along with the ability to perform activities of daily living. As shown in Figure 2, eight patients shifted from A to B, two patients shifted from $\mathrm{A}$ to $\mathrm{C}$, and one from $\mathrm{B}$ to $\mathrm{C}$ on the ASIA scale. These numbers are small because of the limitations in recording of the ASIA scale, ie, it is not sensitive enough to detect partial recovery. This indicates a need to use more sensitive measures to monitor recovery in SCI patients following cell therapy.

Finally, a significant number of patients (59.59\%) showed an increase in their FIM score after cell therapy, which established a statistically significant relationship between the change in FIM score and effect of cell therapy. In addition to improvement in mobility and ability to transfer, functional gains were noted in eating, dressing, and bathing/grooming, which may be attributable to the gains in trunk strength, control, and sitting balance observed in a significant number of patients. The changes in FIM score were highly statistically significant. This enhancement in function led to improved quality of life for these patients.

Lack of a control group is a limitation in this study. However, because of the chronicity of SCI in all the patients included, it was possible for them to act as their own controls. It has been observed that spontaneous recovery occurs until 6-9 months, after which the rate of recovery plateaus. ${ }^{27}$ Because the mean duration since SCI in this study was 5 years and 9 months, it can be assumed that spontaneous recovery had already reached a plateau, hence their ability to serve as their own controls.

\section{Conclusion}

We conclude that the multiple mechanisms of action of BMMNCs promote a reparative process in the damaged spinal cord which was reflected by symptomatic and functional improvement in the majority of our patients with thoracolumbar SCI. This study also reaffirms the safety and viability of intrathecal autologous BMMNC therapy. It is well established that rehabilitation promotes the recovery of neurological deficits, and its amalgamation with cell therapy may augment recovery further. To exploit the potential of cell therapy in SCI patients, further large-scale, sophisticated, multicenter clinical trials are the need of the hour.

\section{Disclosure}

The authors report no conflicts of interest in this work.

\section{References}

1. Hernández J, Torres-Espín A, Navarro X. Adult stem cell transplants for spinal cord injury repair: current state in preclinical research. Curr Stem Cell Res Ther. 2011;6:273-287.

2. Harrop JS, Hashimoto R, Norvell D, et al. Evaluation of clinical experience using cell-based therapies in patients with spinal cord injury: a systematic review. J Neurosurg Spine. 2012;17:230-246.

3. Ozdemir M, Attar A, Kuzu I. Regenerative treatment in spinal cord injury. Curr Stem Cell Res Ther. 2012;7:364-369.

4. Carlson RV, Boyd KM, Webb DJ. The revision of the Declaration of Helsinki: past, present and future. Br J Clin Pharmacol. 2004;57: 695-713.

5. Petit I, Szyper-Kravitz M, Nagler A, et al. G-CSF induces stem cell mobilization by decreasing bone marrow SDF-1 and up-regulating CXCR4. Nat Immunol. 2002;3:687-694.

6. Yoon SH, Shim YS, Park YH, et al. Complete spinal cord injury treatment using autologous bone marrow cell transplantation and bone marrow stimulation with granulocyte macrophage-colony stimulating factor: phase I/II clinical trial. Stem Cells. 2007;25:2066-2073.

7. Hamilton BB, Granger CV, Sherwin FS, Zielezny M, Tashman JS. A uniform national data system for medical rehabilitation. In: Fuhrer MJ, editor. Rehabilitation Outcomes Analysis and Measurement. Baltimore, MD: Brookes PH; 1987.

8. Ottenbacher KJ, Hsu Y, Granger CV, Fiedler RC. The reliability of the Functional Independence Measure: a quantitative review. Arch Phys Med Rehabil. 1996;77:1226-1232.

9. Marino RJ. Neurological and functional outcomes in spinal cord injury: review and recommendations. Top Spinal Cord Inj Rehabil. 2005;10:51-64.

10. Houle JD, Tessler A. Repair of chronic spinal cord injury. Exp Neurol. 2003;182:247-260.

11. Okano H, Ogawa Y, Nakamura M, Kaneko S, Iwanami A, Toyama Y. Transplantation of neural stem cells into the spinal cord after injury. Semin Cell Dev Biol. 2003;14:191-198.

12. Schultz SS. Adult stem cell application in spinal cord injury. Curr Drug Targets. 2005;6:63-73.

13. Gabr H, Ghannam O, Awad MR, von Wild K, El-Kheir WA, Ewes I. Autologous mesenchymal stem cell therapy for spinal cord injury: long term safety and clinical efficacy. Am J Neuroprot Neuroregen. 2011;3:100-106.

14. Zhou XH, Ning GZ, Feng SQ, et al. Transplantation of autologous activated Schwann cells in the treatment of spinal cord injury: six cases, more than five years of follow-up. Cell Transplant. 2012;21: S39-S47.

15. Ohta M, Suzuki Y, Noda T, et al. Bone marrow stromal cells infused into the cerebrospinal fluid promote functional recovery of the injured rat spinal cord with reduced cavity formation. Exp Neurol. 2004; 187:266-278.

16. Lawall H, Bramlage P, Amann B. Stem cell and progenitor cell therapy in peripheral artery disease. A critical appraisal. Thromb Haemost. 2010;103:696-709. 
17. Pösel C, Möller K, Fröhlich W, Schulz I, Boltze J, Wagner DC. Density gradient centrifugation compromises bone marrow mononuclear cell yield. PLoS One. 2012;7:e50293.

18. Saito F, Nakatani T, Iwase M, et al. Spinal cord injury treatment with intrathecal autologous bone marrow stromal cell transplantation: the first clinical trial case report. J Trauma. 2008;64:53-59.

19. Bai H, Suzuki Y, Noda T, et al. Dissemination and proliferation of neural stem cells on the spinal cord by injection into the fourth ventricle of the rat: a method for cell transplantation. J Neurosci Methods. 2003;124:181-187.

20. Vandervelde S, van Luyn MJ, Tio RA, Harmsen MC. Signaling factors in stem cell mediated repair of infarcted myocardium. J Mol Cell Cardiol. 2005;39:363-376.

21. Samdani AF, Paul C, Betz RR, Fischer I, Neuhuber B. Transplantation of human marrow stromal cells and mono-nuclear bone marrow cells into the injured spinal cord: a comparative study. Spine (Phila Pa 1976). 2009;34:2605-2612.

22. Kamei N, Kwon SM, Kawamoto A, et al. Contribution of bone marrow-derived endothelial progenitor cells to neovascularization and astrogliosis following spinal cord injury. J Neurosci Res. 2012;90: 2281-2292.
23. Bakshi A, Barshinger AL, Swanger SA, et al. Lumbar puncture delivery of bone marrow stromal cells in spinal cord contusion: a novel method for minimally invasive cell transplantation. $J$ Neurotrauma. 2006;23:55-65.

24. Paul C, Samdani AF, Betz RR, Fischer I, Neuhuber B. Grafting of human bone marrow stromal cells into spinal cord injury: a comparison of delivery methods. Spine (Phila Pa 1976). 2009;34:328-334.

25. Carvalho KA, Cunha RC, Vialle EN, et al. Functional outcome of bone marrow stem cells (CD45(+)/CD34(-)) after cell therapy in acute spinal cord injury: in exercise training and in sedentary rats. Transplant Proc. 2008;40:847-849.

26. Marosi K, Felszeghy K, Mehra RD, Radák Z, Nyakas C. Are the neuroprotective effects of estradiol and physical exercise comparable during ageing in female rats? Biogerontology. 2012;13:413-427.

27. McDonald JW, Becker D, Sadowsky CL, Jane JA Sr, Conturo TE, Schultz LM. Late recovery following spinal cord injury: case report and review of the literature. J Neurosurg. 2002;97:252-265.

\section{Publish your work in this journal}

The Journal of Neurorestoratology is an international, peer-reviewed, open access online journal publishing original research and review articles on the subject of Neurorestoratology. To provide complete coverage of this revolutionary field the Journal of Neurorestoratology will report on relevant experimental research, technological advances, and

\section{Dovepress}

clinical achievements. The manuscript management system is completely online and includes a very quick and fair peer-review system, which is all easy to use. Visit http://www.dovepress.com/testimonials.php to read real quotes from published authors.

Submit your manuscript here: http://www.dovepress.com/journal-of-neurorestoratology-journal 